Article

\title{
The AtHSP17.4C1 Gene Expression Is Mediated by Diverse Signals that Link Biotic and Abiotic Stress Factors with ROS and Can Be a Useful Molecular Marker for Oxidative Stress
}

\author{
Nasser Sewelam ${ }^{1,2, *}$, Kemal Kazan $^{3,4}$, Meike Hüdig ${ }^{1}$, , Veronica G. Maurino ${ }^{1}$ and \\ Peer M. Schenk ${ }^{5}$ \\ 1 Plant Molecular Physiology and Biotechnology Group, Institute of Developmental and Molecular Biology of \\ Plants, Heinrich Heine University, and Cluster of Excellence on Plant Sciences (CEPLAS), Düsseldorf 40225, \\ Germany \\ 2 Botany Department, Faculty of Science, Tanta University, Tanta 31527, Egypt \\ 3 Commonwealth Scientific and Industrial Research Organisation (CSIRO) Agriculture, Queensland \\ Bioscience Precinct, St Lucia, Queensland 4067, Australia \\ 4 Queensland Alliance for Agriculture and Food Innovation, University of Queensland, St Lucia, Queensland \\ 4072, Australia \\ 5 Plant-Microbe Interactions Laboratory, School of Agriculture and Food Sciences, The University of \\ Queensland, Brisbane, Queensland 4072, Australia \\ * Correspondence: sewelam@science.tanta.edu.eg
}

Received: 26 April 2019; Accepted: 27 June 2019; Published: 29 June 2019

\begin{abstract}
Reactive oxygen species (ROS) are highly controlled signaling species that are involved in regulating gene expression in response to different environmental cues. The production of heat shock proteins (HSPs) is a key strategy that plants use to defend themselves against diverse stresses, including oxidative stress. In this study, expression patterns of the Arabidopsis HSP17.4CI gene, a cytosolic class I small HSP, were systematically profiled under different abiotic, biotic and oxidative stresses. Our data show that HSP17.4CI was early and highly induced by heat, cold, salt, drought and high-light. HSP17.4CI also showed high expression levels in Arabidopsis plants infected with the biotrophic pathogen Pseudomonas syringae, but not in response to the necrotrophic pathogens Alternaria brassicicola and Fusarium oxysporum. Oxidative stress treatments including $\mathrm{H}_{2} \mathrm{O}_{2}$ and the herbicide methyl viologen led to induction of HSP17.4CI. The plant hormones abscisic acid (ABA) and salicylic acid (SA) induced the expression of HSP17.4CI, whereas methyl jasmonate (MJ) did not affect the expression level of this gene. Furthermore, we found enhanced expression of HSP17.4CI in catalase mutant plants, which are deficient in catalase 2 activity and accumulate intracellular $\mathrm{H}_{2} \mathrm{O}_{2}$. Taken together, data presented here suggest that $\mathrm{HSP} 17.4 \mathrm{CI}$ expression is regulated by various signals that connect biotic and abiotic stresses with ROS and can be used as a molecular marker for oxidative stress.
\end{abstract}

Keywords: Reactive oxygen species; small heat shock proteins; abiotic stress; biotic stress; abscisic acid; salicylic acid

\section{Introduction}

Plants are continuously subjected to a broad range of biotic and abiotic stresses that negatively affect plant productivity. Therefore, revealing the relevant mechanisms of plant responses to stress is of great importance. Available evidence suggests that reactive oxygen species (ROS) production in plants is a common response to almost all environmental challenges [1-3]. ROS work as highly controlled 
signaling species that are able to deliver different environmental cues to the plant cell transcriptional machinery [4-9]. This signaling function of ROS is becoming more operative through their interactions with other various signaling components including phytohormones, $G$ proteins, calcium ions and mitogen-activated protein kinases (MAPKs) [7]. Furthermore, ROS are reported to mediate cellular signals through direct interaction with transcription factors, including heat shock factors (HSFs). For example, HSFA2 and HSFA4A were reported to be induced by oxidative stress and involved in $\mathrm{H}_{2} \mathrm{O}_{2}$ sensing $[10,11]$.

$\mathrm{H}_{2} \mathrm{O}_{2}$, the most widespread cellular ROS, is an uncharged molecule that defuses readily through biological membranes [12,13] and thus can efficiently deliver intracellular systemic signals [7]. Indeed, $\mathrm{H}_{2} \mathrm{O}_{2}$ has the ability to modulate the expressional behavior of many genes in various organisms. The expression of about one-third of Saccharomyces cerevisiae genes was shown to be modulated upon exposure to $\mathrm{H}_{2} \mathrm{O}_{2}$ [14]. In Arabidopsis, 175 out of 11,000 non-redundant expressed sequence tags were found to be regulated by $\mathrm{H}_{2} \mathrm{O}_{2}$ treatment [15]. Similarly, production of $\mathrm{H}_{2} \mathrm{O}_{2}$ in chloroplasts of Arabidopsis plants treated with methyl viologen led to the differential expression of a large number of genes, with heat shock proteins (HSPs) being the most abundant group between the upregulated genes [16].

Various HSPs are produced in plants under environmental stress conditions such as high temperature, drought, salinity, osmotic, cold and oxidative stresses [17-23]. It is widely accepted that HSPs play a crucial role in protecting cell structures against stress in plants and other organisms [24-29]. Small HSPs (sHSPs) are the most abundant HSPs that are produced universally in prokaryotic and eukaryotic cells upon heat stress [30,31]. In Arabidopsis, sHSP genes are not expressed in unstressed tissues but show high levels of gene expression during heat stress and other environmental challenges $[25,32,33]$. A number of sHSPs were highly induced on exposure of Arabidopsis plants to heat, osmotic and salinity; with the induction of these genes were more pronounced under a combined treatment of these three stresses [34]. High levels of sHSP gene expression and protein accumulation upon environmental stresses support the hypothesis that these proteins play an important role in stress tolerance [35,36].

For cell survival under stress conditions, the maintenance of proteins in their functional conformations and the prevention of the aggregation of non-native proteins are particularly important. In this regard, HSPs are involved in stabilizing proteins and membranes, and thus they can assist protein refolding under stress conditions [24,37-39]. It was reported that sHSPs represent the first line of defense in the cell to prevent protein misfolding [40]. Certain sHSPs, such as HSP18.1 isolated from pea (Pisum sativum) and HSP16.6 from Synechocystis sp. PCC6803, were shown to bind to unfolded proteins in vitro and this enables further refolding by HSP70/HSP100 complexes [41]. In addition to their chaperone function, it is also suggested that sHSPs modulate fluidity and composition of cell membranes [42].

sHSPs have roles in protection against oxidative stress. For example, overexpression of chloroplastic sHSPs in tomato (HSP21) and tobacco (HSP26) provided evidence that these sHSP protect photosystem II from oxidative stress [43,44]. The overexpression of an sHSP (LimHSP16.45) from the David lily (Lilium davidii) in Arabidopsis led to enhanced cell viability under high temperatures, salinity, and oxidative stress [45]. In addition, LimHSP16.45 overexpressing plants showed greater activity of superoxide dismutase and catalase than control plants, suggesting that LimHSP16.45 can protect plants against abiotic stresses by enhancing enzymes that scavenge ROS, in addition to their roles in preventing irreversible protein aggregation [45].

In previous work, we found that the expression level of the Arabidopsis sHSP gene, HSP17.4CI, was highly induced by heat, salt and drought $[34,46]$. This finding attracted our attention to further study the dynamic changes in expression patterns of this gene under a wide range of stresses. We were particularly interested in finding out the specific patterns of HSP17.4CI expression that would shed light on the modes by which different environmental challenges modulate gene expression. Here, we investigated the expression patterns of $\mathrm{HSP} 17.4 \mathrm{CI}$ under various abiotic, biotic and oxidative stresses, 
as well as after treatment with stress-related phytohormones. The expression of HSP17.4CI was significantly enhanced by stresses that involve ROS production such as heat, cold, salt, drought, high light, the biotrophic pathogen Pseudomonas syringae, in addition to phytohormones such as abscisic acid (ABA) and salicylic acid (SA) that are involved in mediating signals of these stresses. Furthermore, by using mutant plants that are deficient in catalase 2 activity and consequently accumulate endogenous $\mathrm{H}_{2} \mathrm{O}_{2}$, we have supported the proposal that the induction of $H S P 17.4 \mathrm{CI}$ is modulated by ROS, where its expression was significantly induced in these cat 2 loss-of-function mutants.

\section{Results}

\subsection{The Expression of HSP17.4CI is Induced by Various Abiotic Stresses}

To systematically profile the expression pattern of the Arabidopsis $H S P 17.4 C I$, encoding a cytosolic sHSP, under various stress treatments, we first studied the effect of different abiotic stresses (including heat, cold, salt, drought and high light stress treatments) on the expression pattern of the AtHSP17.4CI gene. Various growth media used here and sampling time points for each treatment were selected based on previous work [e.g., 46, and references therein]. Our results show that exposure to a heat dose of $45^{\circ} \mathrm{C}$ for $2 \mathrm{~h}$, dramatically induced HSP17.4CI transcript levels (Figure 1A). The effect of prolonged heat shock at $45^{\circ} \mathrm{C}$ for 4 or $6 \mathrm{~h}$ on $\mathrm{HSP} 17.4 \mathrm{CI}$ expression was similar to that observed at $2 \mathrm{~h}$. These results show that $H S P 17.4 C I$ has very low basal expression levels in unstressed plants, but is strongly induced by heat stress. This finding is consistent with previous reports indicating that under normal growth conditions, transcripts of most sHSPs cannot be detected in vegetative tissues, but are rapidly produced in response to heat [35]. The present results also show that cold treatment at $0{ }^{\circ} \mathrm{C}$ for 3 $\mathrm{h}$ upregulated HSP17.4CI expression by more than 4 -fold compared to control, with no additional significant increase in the expression level after prolonged cold exposures of 6 or $12 \mathrm{~h}$ (Figure 1B). Under salt stress, HSP17.4CI was induced by more than 3-fold after $2 \mathrm{~h}$ of treatment and 7-fold after 6 $\mathrm{h}$. After $10 \mathrm{~h}$ of salt treatment no additional increase in HSP17.4CI transcript abundance was detected (Figure 1C).

Results presented in Figure 1D show that drought treatment led to upregulation of HSP17.4CI by about 2 -fold after $1 \mathrm{~h}$ and by more than 4 -fold at $2 \mathrm{~h}$ after the treatment. However, there was no detectable increase compared to control after shorter period of $30 \mathrm{~min}$. Furthermore, our results show that HSP17.4CI was induced by high-light stress (Figure 1E). Compared to the control, transcript levels of HSP17.4CI increased 10 times after $6 \mathrm{~h}$, and 15 times after $12 \mathrm{~h}$ of high light exposure at $800 \mu \mathrm{E}$ (Figure 1E). Altogether, these data indicate that the expression level of the HSP17.4CI gene is significantly induced by various abiotic stress treatments. 
A

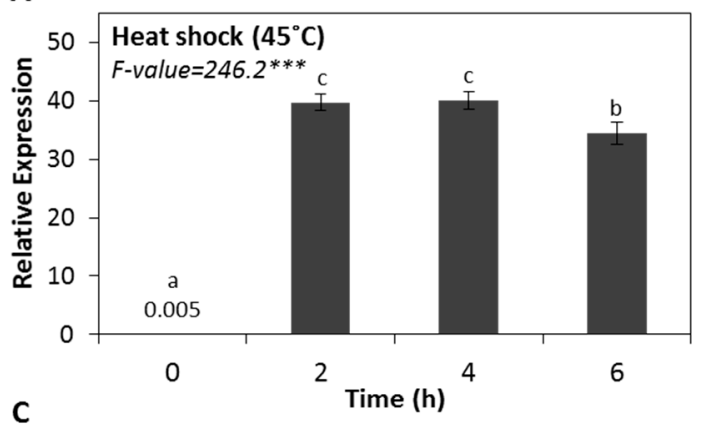

C

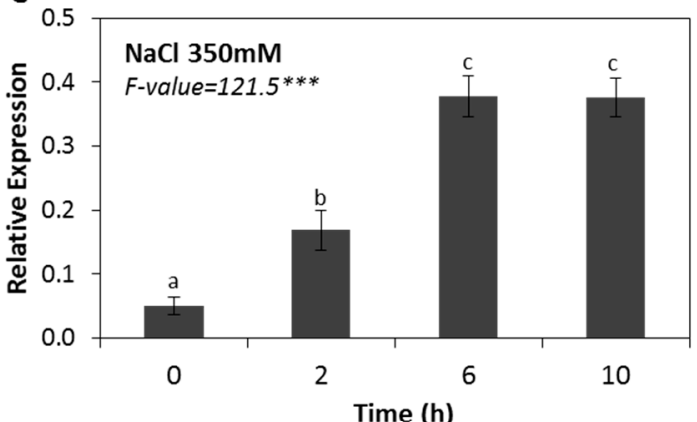

$\mathbf{E}$

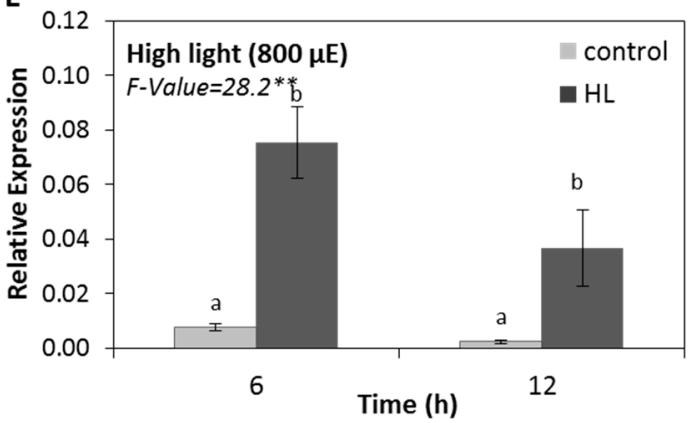

B

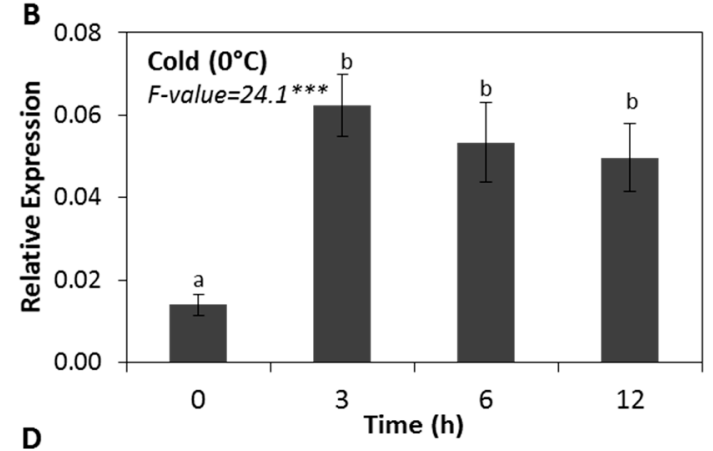

D

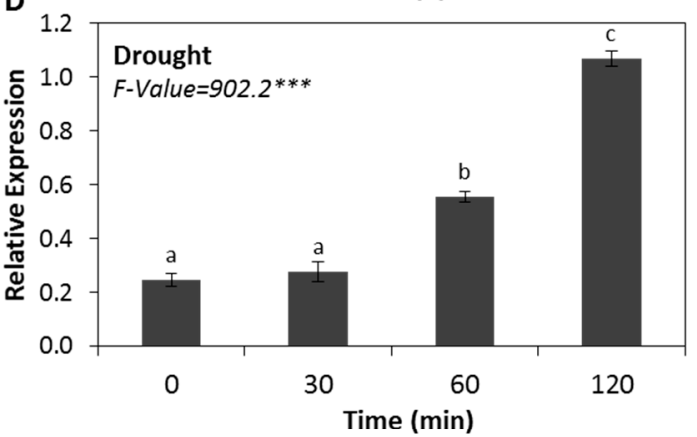

Figure 1. Effect of various abiotic stress treatments on HSP17.4CI expression in Arabidopsis. (A) heat $\left(45^{\circ} \mathrm{C}\right),(\mathbf{B})$ cold $\left(0^{\circ} \mathrm{C}\right),(\mathbf{C})$ salt $(350 \mathrm{mM}),(\mathbf{D})$ drought (plants kept on dry filter paper), (E) high light $\left(800 \mu \mathrm{mol}\right.$ photons. $\left.\mathrm{m}^{-2} \cdot \mathrm{s}^{-1}\right)$. Data represents the average and SDs from three biological replicates. F-values represent one-way ANOVA. ${ }^{* *}: p<0.01{ }^{* * *}: p<0.001$. Means with different letters are significantly different at $p<0.05$ according to the Tukey HSD test. For panel (E), different letters at the same time point indicate significant differences.

\subsection{HSP17.4CI is Responsive to Biotrophic but Not to Necrotrophic Pathogens}

In addition to their roles in plant tolerance to abiotic stresses, HSPs were reported to play a role in plant defense against biotic stresses [47]. Here, we studied the effect of different pathogens on the expression of the Arabidopsis HSP17.4CI. Our study included the biotrophic pathogen Pseudomonas syringae, and the necrotrophic pathogens Alternaria brassicicola and Fusarium oxysporum. We observed no changes in the expression levels of HSP17.4CI at $6 \mathrm{~h}$ after inoculation of Arabidopsis plants with P. syringae (Figure 2A). However, after $24 \mathrm{~h}$ from inoculation we observed an increase of HSP17.4CI expression by more than 8-fold compared to the mock-treated control. After $48 \mathrm{~h}$ from inoculation, the expression level of HSP17.4CI was lower than that after 24 hours, but still 4-times higher than the corresponding mock treated control, suggesting a relatively early role for HSP17.4CI during defense against this biotrophic pathogen. In contrast, no changes in the expression level of HSP17.4CI were found after infection with the necrotrophic pathogens A. brassicicola or F. oxysporum at any of the indicated time points (Figure 2B,C). 

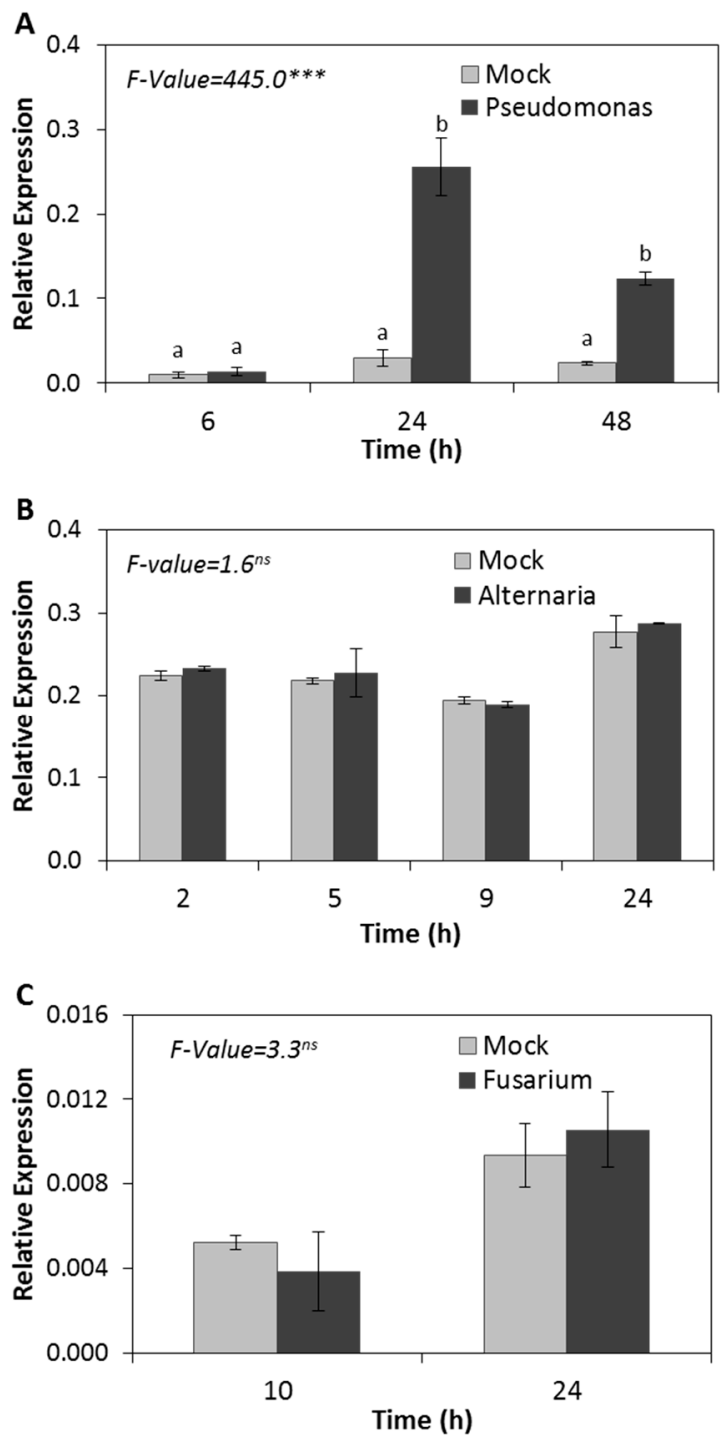

Figure 2. Effect of various biotic stress treatments on HSP17.4CI expression in Arabidopsis. (A) Pseudomonas syringae, (B) Alternaria brassicicola, (C) Fusarium oxysporum. Shown are average values and SDs of three biological replicates. F-values represent one-way ANOVA. ${ }^{* *}: p<0.001$, ns: not significant. Means with different letters at each time point are significantly different at $p<0.05$ according to the Tukey HSD test.

\subsection{HSP17.4CI is Upregulated by Plant Hormones ABA and SA but Not by MJ}

Plant responses to different abiotic and biotic environmental stresses are coordinated by plant hormones such as ABA, SA, and MJ. To investigate the involvement of these plant hormones in the modulation of the expression of HSP17.4CI, the transcript level of this gene was monitored in Arabidopsis plants after hormone treatment. Our results show that the $H S P 17.4 C I$ expression level was significantly increased at 1, 4 and $24 \mathrm{~h}$ after ABA treatment, reaching more than 4 -fold increase after $24 \mathrm{~h}$ compared to the control (Figure $3 \mathrm{~A}$ ). Considering the suggestion that ABA regulates plant responses to various abiotic stresses, the induction of HSP17.4CI by ABA is in line with HSP17.4CI induction by the applied stresses shown in Figure 1. 

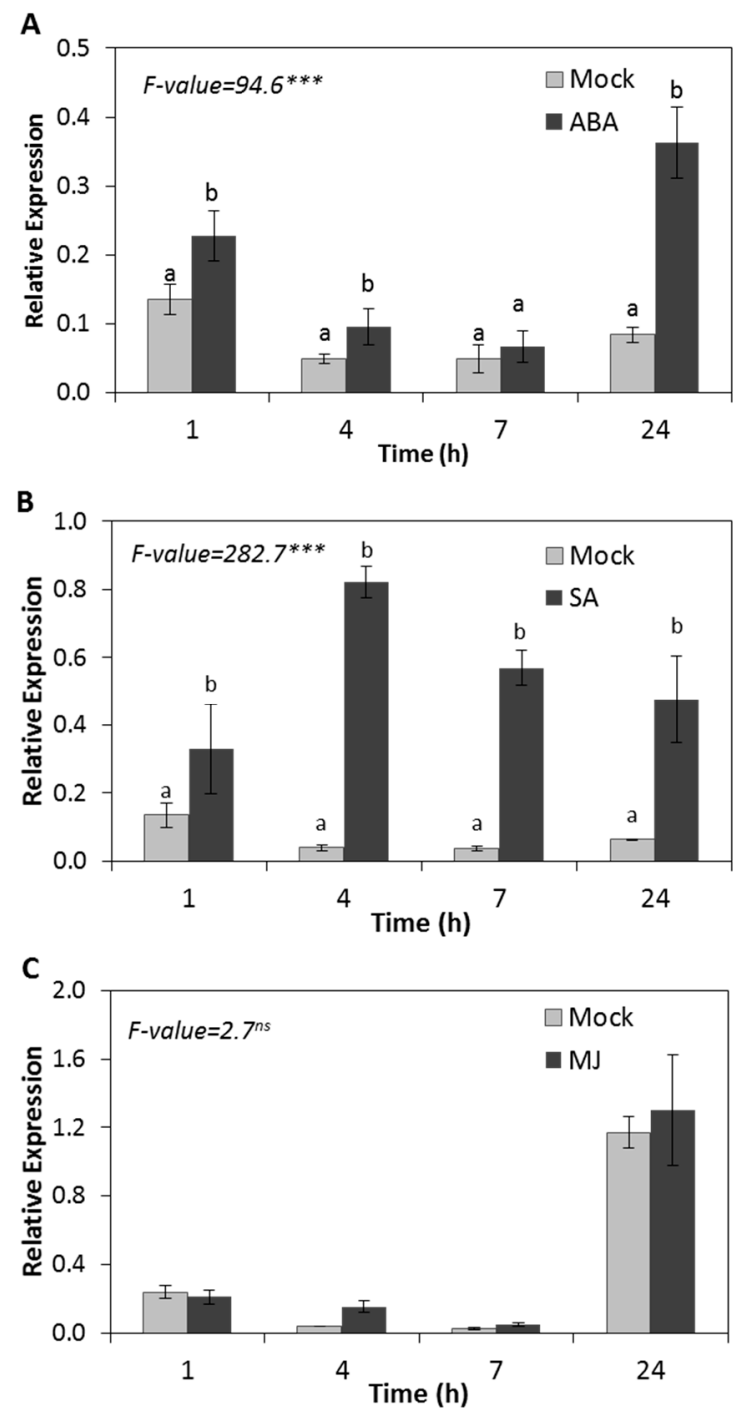

Figure 3. Effect of various plant hormone treatments on $H S P 17.4 C I$ expression in Arabidopsis. (A) abscisic acid (ABA, $400 \mu \mathrm{M}),($ B) salicylic acid (SA, $4 \mathrm{mM}$ ), (C) methyl jasmonate (MJ, $0.1 \mu \mathrm{M}$ per liter of air). Data represent the average and SDs of three biological replicates. F-values represent one-way ANOVA. ${ }^{* *}: p<0.001$, ns: not significant. Means with different letters at each time point are significantly different at $p<0.05$ according to the Tukey HSD test.

The plant hormone SA is known to be involved in plant growth and development and plays a role during defense against biotrophic pathogens [48]. To investigate the possible involvement of SA in the induction of HSP17.4CI by the biotrophic pathogen P. syringe (Figure 2A), we analyzed HSP17.4CI expression in plants treated with SA. Our results show that treating Arabidopsis seedlings with SA significantly induced HSP17.4CI at all of the examined time points (Figure 3B). These results are consistent with the induction of this sHSP by the biotrophic pathogen, P. syringae (Figure 2A) that activates SA signaling [49]. In contrast to ABA and SA, MJ treatment showed no significant effect on HSP17.4CI expression in the treated Arabidopsis plants at any of the investigated time points (Figure $3 C$ ). This result is in line with the finding that the expression level of this gene was not affected by the necrotrophic pathogens A. brassicicola and F. oxysporum (Figure 2B,C), to which the MJ signaling pathway is known to be involved in plant defense [49]. 


\subsection{HSP17.4CI is Strongly Upregulated by Oxidative Stress Treatments}

A general role of sHSPs in oxidative stress tolerance was presumed by observations that production and accumulation of plant sHSPs increase in response to $\mathrm{H}_{2} \mathrm{O}_{2}$ treatments in vitro $[35,50]$. We found that the expression level of $H S P 17.4 C I$ was strongly induced in Arabidopsis plants treated with $\mathrm{H}_{2} \mathrm{O}_{2}$ (Figure $4 \mathrm{~A}$ ). After only $3 \mathrm{~h}$ of $\mathrm{H}_{2} \mathrm{O}_{2}$ treatment, we observed 130-fold higher expression levels than those of the control samples. Similarly, as shown in Figure 4B, transcript levels of HSP17.4CI were strongly increased after treatment with methyl viologen, a herbicide that produces superoxide radicals which are converted into $\mathrm{H}_{2} \mathrm{O}_{2}$ by plant superoxide dismutase in chloroplasts. We found that after $2 \mathrm{~h}$ of treatment with methyl viologen, the expression level of HSP17.4CI was 21-times higher than the untreated control, reaching a maximum level of 71-times higher than the control plants after $4 \mathrm{~h}$ (Figure 4B).
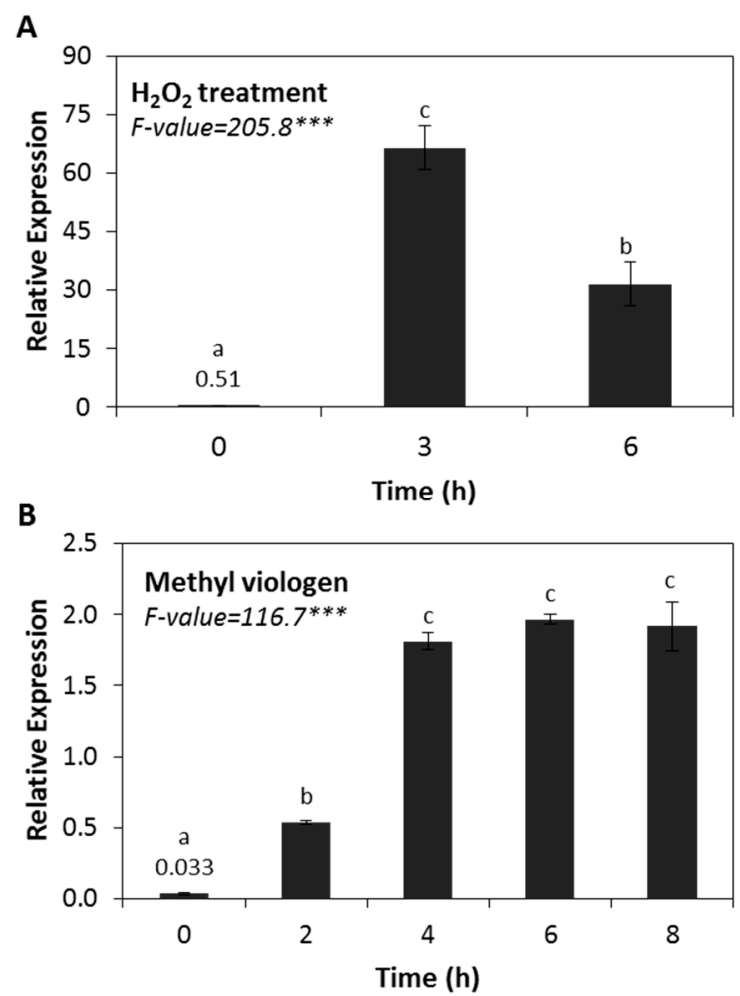

Figure 4. Effect of various oxidative stress treatments on HSP17.4CI expression in Arabidopsis. (A) $\mathrm{H}_{2} \mathrm{O}_{2}$ treatment $(500 \mathrm{mM})$, (B) methyl viologen treatment $(30 \mu \mathrm{M})$. Shown are average values and SDs of three biological replicates. F-values represent one-way ANOVA. ${ }^{* * *}: p<0.001$. Means with different letters are significantly different at $p<0.05$ according to the Tukey HSD test.

\subsection{HSP17.4CI Expression is Enhanced in Mutant Plants that Accumulate Endogenous $\mathrm{H}_{2} \mathrm{O}_{2}$}

To further examine the hypothesis that the observed induction of HSP17.4CI under various stress conditions may be mediated by the production of ROS, we used a photorespiratory mutant deficient in catalase 2 activity (cat2-2), which accumulate $\mathrm{H}_{2} \mathrm{O}_{2}$ under normal air conditions [6,51]. We found that the expression level of HSP17.4CI in the cat2-2 mutant seedlings was significantly higher than that of the wild type grown in the same conditions (Figure 5A). As expected, we found that the $\mathrm{H}_{2} \mathrm{O}_{2}$ content in cat2-2 seedlings was significantly higher than that in the wild type (Figure 5B). These data reinforce the hypothesis that the induction of HSP17.4CI under various abiotic and biotic stresses would be at least partly mediated by ROS. 

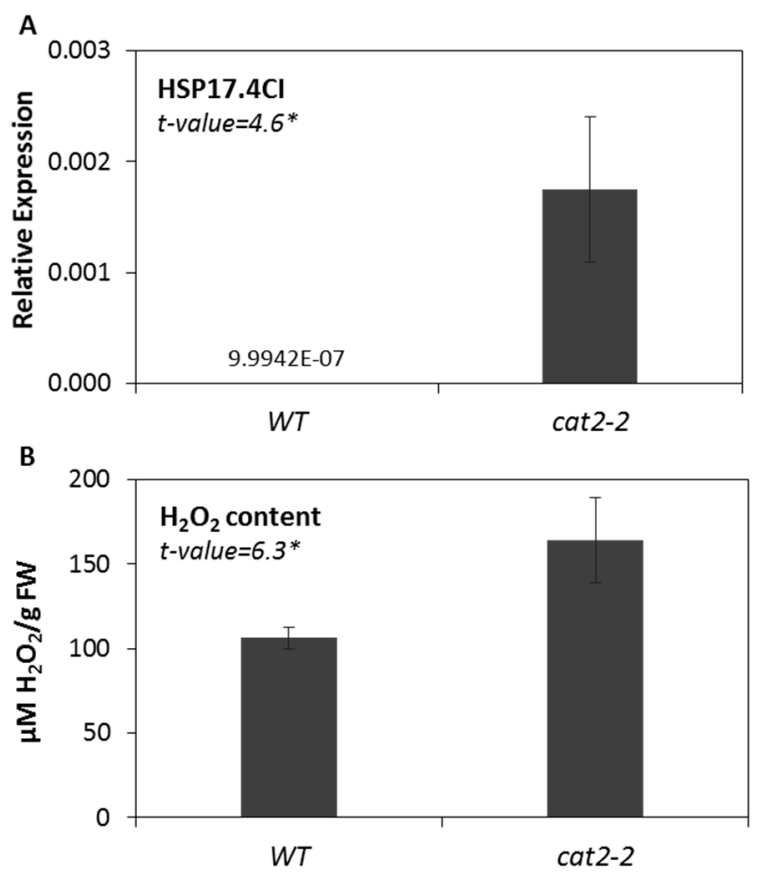

Figure 5. The expression level of $\mathrm{HSP17.4CI}$ (A), and $\mathrm{H}_{2} \mathrm{O}_{2}$ content (B) in wild type (WT) and cat2-2 mutant Arabidopsis plants. For HSP17.4CI expression experiment, data represents the average and SDs of three biological replicates. For $\mathrm{H}_{2} \mathrm{O}_{2}$ quantification experiment, two biological replicates, with three technical replicates each were used. t-values represent Student's t-test. *: $p<0.05$.

\subsection{Responsiveness of the Arabidopsis sHSPs genes to stress factors}

To investigate whether the expression profiles monitored in the current study for the cytosolic sHSP, HSP17.4CI, may be shared by other sHSPs, we first cross-examined the Arabidopsis genome for genes annotated as sHSPs [accessed in 34]. A number of 36 genes were found to be annotated as sHSPs or HSP20-like chaperones (Table S1). We considered genome-wide expression data for a number of different stress treatments including heat, drought and salinity [42], as well as oxidative stresses imposed by $\mathrm{H}_{2} \mathrm{O}_{2}$ [52] and methyl viologen [16]. As plants in their natural habitats are usually subjected to combined stresses, and plant response to these combinations cannot be predicted form their responses to individual ones, we also included expression data of $\mathrm{HSP} 17.4 \mathrm{CI}$ and other sHSPs under a combined treatment of heat, osmotic and salinity [34]. In this study [34], HSP17.4 was reported to be highly induced by combined stress treatment of heat, drought and salinity. Out of the 36 sHSPs, we found that the expression of 19 genes was differentially expressed by at least on stress treatment (Table 1). Only, HSP17.6C showed similar expression pattern to HSP17.4CI under the considered abiotic and oxidative stress treatments. With exception of drought stress, another three genes (HSP17.6A, HSP17.6 and HSP23.5) were induced by heat, salinity and combined treatments, in addition to oxidative stresses imposed by $\mathrm{H}_{2} \mathrm{O}_{2}$ and methyl viologen (Table 1). Furthermore, another four genes (HSP17.6B, HSP17.6A, HSP17.4B and HSP15.7) were induced only by heat and oxidative stresses (Table 1). Notably, two HSP20-like chaperone genes were repressed by multiple (AT4G21870) or heat (AT1G76770) stresses, but not responsive to any of the other treatments. 
Table 1. List of Arabidopsis genes annotated as small heat shock proteins (sHSPs) or HSP20-like chaperones and showed expression responsiveness to stress treatments.

\begin{tabular}{lcccccccc}
\hline \multirow{2}{*}{ Gene Locus } & \multirow{2}{*}{ Gene Name } & \multicolumn{9}{c}{ Expression Levels (Log FC) under Stress Treatments } & \multirow{2}{*}{ Localization } \\
\cline { 3 - 7 } & & Heat & Drought & Salt & Multiple & $\mathbf{H}_{\mathbf{2}} \mathbf{O}_{\mathbf{2}}$ & $\mathbf{M V}$ & \\
\hline AT3G46230 & HSP17.4CI & 6.12 & 1.50 & 2.00 & 7.16 & 3.52 & 4.28 & Cytoplasm \\
AT1G53540 & HSP17.6C & 9.08 & 1.50 & 3.14 & 10.18 & 4.08 & 3.07 & Cytoplasm \\
AT5G12030 & HSP17.6A & 8.72 & - & 2.89 & 9.21 & 3.70 & 5.21 & Cytoplasm \\
AT5G12020 & $H S P 17.6$ & 7.53 & - & 1.97 & 8.22 & 4.89 & 4.04 & Cytoplasm \\
AT5G51440 & $H S P 23.5$ & 6.34 & - & 1.50 & 6.73 & 3.64 & 2.02 & Mitochondrion \\
AT2G29500 & HSP17.6B & 5.76 & - & - & 7.23 & 4.23 & 4.48 & Cytoplasm \\
AT1G59860 & HSP17.6A & 4.52 & - & - & 5.06 & 4.73 & 4.63 & Cytoplasm \\
AT1G54050 & HSP17.4B & 2.44 & - & - & 3.03 & 3.64 & 4.08 & Cytoplasm \\
AT5G37670 & HSP15.7 & 2.71 & - & - & 2.95 & 2.85 & 1.85 & Peroxisome \\
AT4G10250 & HSP22.0 & 8.33 & - & - & 10.17 & 1.53 & - & ER \\
AT4G27670 & $H S P 21$ & 8.02 & - & - & 10.04 & 1.61 & - & Chloroplast \\
AT4G25200 & $H S P 23.6$ & 11.23 & - & 2.73 & 12.12 & - & - & Mitochondrion \\
AT1G07400 & HSP17.8 & 5.96 & - & 1.50 & 6.91 & - & - & Cytoplasm \\
AT2G19310 & HSP18.5 & 3.47 & - & - & 3.37 & - & - & Cytoplasm \\
AT1G52560 & HSP26.5 & 2.40 & - & - & 5.12 & - & - & Mitochondrion \\
AT5G59720 & HSP18.2 & 1.99 & - & - & 3.98 & - & - & Cytoplasm \\
AT4G16550 & HSP20-like chaperone & 1.60 & 2.17 & 1.50 & 1.82 & - & - & Unknown \\
AT4G21870 & HSP20-like chaperone & - & - & - & -2.32 & - & - & Cytoplasm \\
AT1G76770 & HSP20-like chaperone & -1.79 & - & - & - & - & - & Cytoplasm \\
\hline
\end{tabular}

Data for heat $\left(35^{\circ} \mathrm{C}, 4 \mathrm{~h}\right)$, drought (imposed by mannitol, $\left.200 \mathrm{mM}, 16 \mathrm{~h}\right)$, salt $(\mathrm{NaCl}, 150 \mathrm{mM}, 16 \mathrm{~h}$ ) and multiple (a combination of the previous three stresses), was adopted from our previous work [42]. For $\mathrm{H}_{2} \mathrm{O}_{2}(20 \mathrm{mM}, 1 \mathrm{~h})$ and MV (methyl viologen, $50 \mu \mathrm{M}, 2 \mathrm{~h}$ ), data was quoted from [52] and [16], respectively. The gene names and their subcellular locations were quoted from Uniport [53] and The Arabidopsis Information Resource (TAIR) [54] websites. Expression values with Log FC (fold change) of 1.5 or more compared to controls were considered. All shown values were significantly different at $p<0.05$. The hyphen "- "means not responsive. ER: endoplasmic reticulum. Genes on the list were ordered where genes induced by both abiotic and oxidative stresses come first, then by the level of induction by heat, with the investigated gene, $\mathrm{HSP} 17.4 \mathrm{CI}$, on the top.

To find any correlation between subcellular localization of various sHSP genes and their expression patters, we allocated these genes to their subcellular sites (Table 1 and Table S1). Data showed that the sHSP genes that showed similar responsiveness to the expression of $H S P 17.4 C I$ were localized to cytoplasm except HSP23.5 (mitochondrial) and HSP15.7 (peroxisomal).

\section{Discussion}

ROS produced during adaptation to the majority of relatively mild environmental stresses can act as highly controlled signaling molecules with the ability to deliver different environmental cues to the transcriptional machinery $[1,9,55]$. The induction of HSPs is one important strategy that plants use to protect themselves against different stresses, including oxidative stress $[21,24,32,39,56]$. In view of the proposed protective role of the Arabidopsis cytosolic class I sHSP, HSP17CI, against diverse stress conditions, the aim of the current study was to systematically investigate the expression patterns of HSP17.4CI under a wide range of abiotic, biotic and oxidative stress treatments and to investigate whether the expression of HSP17.4CI gene under different stress conditions could be linked to the production of ROS.

Our results showed that after application of various abiotic stresses, including heat, cold, salinity, drought and high light, the expression level of HSP17.4CI significantly raised compared to controls (Figure 1). The rapid induction of HSP17.4CI, by these treatments suggests that this gene may act in a common protection mechanism against the damaging effects of these stresses. In Arabidopsis, the overexpression of the Medicago sativa MsHSP17.7 increased the tolerance of the transgenic lines to heat shock, high salinity, oxidative and drought stresses [21]; similarly, the overexpression of two rice sHSPs (OsSHSP1 and OsSHSP2) led to higher germination rates compared to wild-type plants under salt treatment [57]. 
HSPs were reported to be involved in plant defense responses following biotic stress $[47,58,59]$. Here, we studied the effect of infection with different pathogens on HSP17.4CI. Our data show that the inoculation of Arabidopsis plants with P. syringae led to an increase of HSP17.4CI expression (Figure 2A), suggesting the role of $H S P 17.4 C I$ during defense against this biotrophic pathogen. In contrast, no significant change in the expression level of HSP17.4CI was noticed after infection with the necrotrophic pathogens, A. brassicicola or F. oxysporum (Figure 2B,C). Based on the mode of infection of the biotrophic pathogens that feed on living plant cells and the necrotrophic pathogens that feed on dead cells, plants defend themselves against biotrophic pathogens by rapid induction of an oxidative burst (excessive production of ROS) that leads to hypersensitive response and programmed cell death, while in the case of necrotrophic pathogens, the infected plants respond by avoiding the production of ROS [49]. Thus, the reported upregulation of HSP17.4CI by biotrophic but not necrotrophic pathogens suggests that the expression of this sHSP may be at least partially mediated by ROS.

Phytohormones such as ABA, SA, and MJ orchestrate plant responses to different abiotic and biotic environmental stresses [60]. We found that Arabidopsis seedlings treated with ABA have enhanced relative transcription levels of HSP17.4CI compared with the untreated control (Figure 3A). Considering the fact that $\mathrm{ABA}$ mediates plant responses to various abiotic stresses, especially drought stress, the induction of $H S P 17.4 C I$ expression by ABA is consistent with the induction of expression observed after drought stress treatment (Figure 1D). This suggests that the upregulation of expression of this sHSP by drought could be mediated by ABA signaling, which could integrate a cross-talk with ROS [61,62]. Furthermore, we found that the expression of HSP17.4CI rapidly increased after treatment with SA (Figure 3B). These results are in line with the induction of expression of HSP17.4CI by infection with the biotrophic pathogen P. syringae (Figure 2A), which activates SA signaling [49]. MJ treatment showed no effect on the expression level of HSP17.4CI in Arabidopsis seedlings (Figure 3C). This result is consistent with the finding that the expression level of HSP17.4CI gene was not affected by A. brassicicola (Figure 2B) and F. oxysporum (Figure 2C), where MJ signaling pathway is known to be involved in plant defense against these pathogens [49]. The modulation of expression of $\mathrm{HSP} 17.4 \mathrm{CI}$ observed after treatment with phytohormones, and abiotic and biotic stresses suggests that environmental stresses might influence the expression of HSP17.4CI through a cross-talk between hormonal and ROS signaling.

Indeed, almost all environmental stresses enhance ROS production $[63,64]$. The participation of ROS generated during the applied abiotic and biotic stresses in the induction of HSP17.4CI (Figures 1 and 2) is supported by the finding that treatment with cellular oxidants, such as $\mathrm{H}_{2} \mathrm{O}_{2}$ and methyl viologen, also enhanced the expression level of HSP17.4CI (Figure 4). These results are in line with the knowledge that expression of various plant sHSPs is increased in response to externally applied oxidative stress $[16,35]$. Moreover, our results showed that expression of HSP17.4CI is also enhanced in catalase loss-of-function plants which accumulate metabolically-produced $\mathrm{H}_{2} \mathrm{O}_{2}$ after their transfer from non-photorespiratory to photorespiratory conditions (Figure 5).

Reviewing the expression profiles of sHSPs in Arabidopsis genome indicated that only one cytosolic sHSP (HSP17.6C) showed identical expression pattern to HSP17.4CI under different stress treatments (Table 1). Both genes were reported to be induced by heat, drought, salinity and their combination [42], as well as by oxidative stresses imposed by $\mathrm{H}_{2} \mathrm{O}_{2}$ [52] or methyl viologen [16]. Another three sHSP genes (HSP17.6A, HSP17.6 and HSP23.5) showed relatively similar expression behaviors under abiotic and oxidative stress treatments (Table 1).

Genes that are regulated by oxidative stress share regulatory elements in their promotor sequences that enable concerted changes in gene expression and downstream signaling events [10]. A small number of newly found motifs in promotor sequences is associated with upregulation of the respective genes upon oxidative stress [11,16]. Two of these motifs, Motif 1 ([A/T][A/T]TGGGCCT[T/A]AA) and Motif 5 (GAA[A/C][G/C]TT[C/G][C/A]AGA), are present in the promoter sequence of HSP17.4CI (Figure 6). Motif 5 is present in a direct tandem repeat, 22 nucleotide upstream of the $5^{\prime}$ untranslated region (UTR) of HSP17.4CI. Motif 1 was found to be more upstream, 219 nucleotide from the start 
of the 5'UTR. Two members of the heat shock transcription factor family, HSFA2 and HSFA4A, are induced by oxidative stress and suggested to be involved in $\mathrm{H}_{2} \mathrm{O}_{2}$ sensing $[10,11]$. Interestingly, the finding that Motif 1 is shared by HSFA2 suggest that HSP17.4CI may be involved in an oxidative stress signaling pathway that uses a specific subset of HSFs and HSPs to integrate oxidative stress in the flexible gene network that controls the plant's response to various environmental stress conditions.

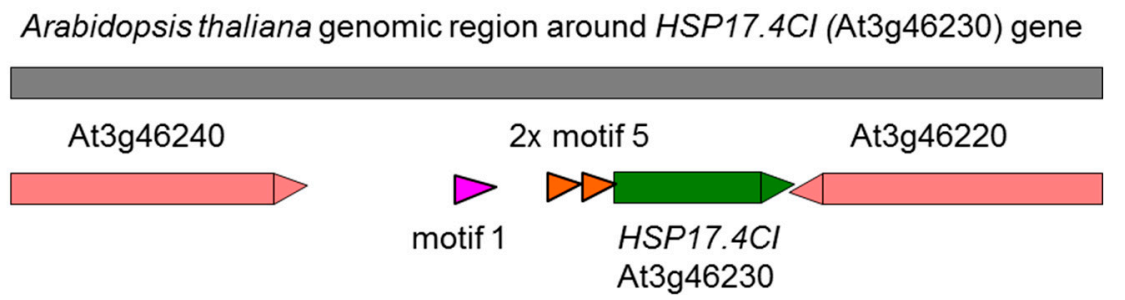

Figure 6. Schematic representation of a 4kb long genomic region surrounding At3g46230 (HSP17.4CI, green). Genes are represented as boxes with indicated gene orientation. The identified oxidative stress motifs in the promotor region are highlighted in pink (Motif 1, existed once) and orange (Motif 5, existed twice and indicated as $2 \mathrm{x}$ ).

In conclusion, the rapid and strong expression of HSP17.4CI under a myriad of stress conditions that involve ROS production, suggests that this gene might play an essential role during oxidative stress mitigation. We propose that HSP17.4CI can be used as molecular marker for oxidative stress in Arabidopsis and that its orthologs, upon further future studies, could represent candidate target genes for engineering stress tolerant crop plants.

\section{Materials and Methods}

\subsection{Plant Materials and Growth Conditions}

Arabidopsis thaliana ecotype Columbia (Col-0, wild type) was used in all experiments. Seeds were stratified at $4{ }^{\circ} \mathrm{C}$ for 2 days and then transferred to the growth cabinets. For plate-grown Arabidopsis plants, seeds were surface-sterilized and sown on 1x MS (Murashige and Skoog) plates [65]. Plants were grown in cabinets at $24{ }^{\circ} \mathrm{C}$ and $15 \mathrm{~h}$ photoperiod at $150 \mu \mathrm{mol}$ photons. $\mathrm{m}^{-2} \cdot \mathrm{s}^{-1}$. Fourteen-day-old Seedlings were exposed for treatments. For soil-grown plants, Arabidopsis seeds were sown on soil (University of California mix) and left to grow in a growth chamber at $24{ }^{\circ} \mathrm{C}$ and $8 \mathrm{~h}$ photoperiod $\left(150 \mu \mathrm{mol}\right.$ photons. $\left.\mathrm{m}^{-2} \cdot \mathrm{s}^{-1}\right)$. After around 10 days, seedlings were transplanted to new soil. Four-week-old seedlings were exposed to different treatments. For control samples, plants were mock-treated/inoculated. The treatments were started $1 \mathrm{~h}$ after the light turned on to allow direct comparisons between treatments. The growth media and the collection time points for each treatment were chosen based on previous work [e.g., 46, and references therein]. For experiments done on soil grown plants, the above ground plant parts were used for the subsequent analyses. In all measurements, three biological replicates for each treatment were used.

\subsection{Abiotic Stress Treatments}

Heat, cold, salt and water stress treatments were carried out on 14-day-old MS plate-grown seedlings. For heat treatment, plates were moved to an incubator at $45^{\circ} \mathrm{C}$ (light intensity was 75 $\mu \mathrm{mol}$ photons. $\mathrm{m}^{-2} \cdot \mathrm{s}^{-1}$ ). Cold treatment was conducted by incubating the plates on ice in a cold room (temperature was about $0^{\circ} \mathrm{C}$ ) for the indicated time points. Salt stress was applied by transferring the seedlings from the MS medium to Petri dishes containing water. After $1 \mathrm{~h}$ recovery, a $\mathrm{NaCl}$ solution was added to make a final concentration of $350 \mathrm{mM}$. Control samples were left without salt. For drought treatment, seedlings were moved from the MS plates to dry filter paper, whereas control seedlings were moved to distilled-water-wetted filter paper. High light stress was imposed by subjecting 4 week-old soil-grown plants to $800 \mu \mathrm{mol}$ photons. $\mathrm{m}^{-2} \cdot \mathrm{s}^{-1}$. 


\subsection{Biotic Stress Treatments}

All pathogen treatments were performed on 4 week-old soil-grown plants. The pathogens used were Pseudomonas syringae, Alternaria brassicicola, and Fusarium oxysporum. For the details of Pseudomonas inoculations see [46]. Alternaria inoculations were carried out as follows: A. brassicicola (isolate UQ4273) was grown on agar plates containing V8 vegetable juice (Campbell Soup Co., Camden, $\mathrm{NJ})$. Drops of $5 \mu \mathrm{L}$ size of a spore suspension $\left(5 \times 10^{5} \mathrm{spores} / \mathrm{mL}\right.$ in water) were pipetted onto three to four leaves per plant (one drop per leaf). The plants were then placed in a $20 \mathrm{~L}$-container with a clear polystyrene dome and kept at high humidity. Mock-inoculated control plants were treated the same way with water instead [66]. Fusarium inoculations were carried out as follows: F. oxysporum was grown on $\frac{1}{2} \mathrm{PDB}$ (Potato Dextrose Broth) agar plates at $28^{\circ} \mathrm{C}$ for one week in the dark. An agar plug was removed from the plate and added to $\frac{1}{2}$ PDB (Potato Dextrose Broth) liquid medium. The inoculum was kept in a shaker for $2 \mathrm{~d}$ at $28{ }^{\circ} \mathrm{C}$ before draining the culture with a sieve. Using a hemocytometer, the spore number was determined, and then the culture was diluted with distilled water to $10^{6}$ spores $/ \mathrm{mL}$. After carefully removing plants from soil, roots were rinsed with distilled water then dipped in the Fusarium spore solution for about $1 \mathrm{~min}$. The inoculated plants were immediately returned to soil and covered with a transparent plastic cover. For the mock-inoculated control roots were dipped in sterilized water instead.

\subsection{Plant Hormone Treatments}

For all hormone treatments, 4-week-old soil-grown plants were used. Solutions of $400 \mu \mathrm{M} \mathrm{ABA}$ or $4 \mathrm{mM} \mathrm{SA}$ in $1 \%$ ethanol was used for plant spraying. Control plants were sprayed with $1 \%$ ethanol solution. In hormone and mock treatments, the $\mathrm{pH}$ was adjusted to 5 . MJ treatment was applied by taping a piece of cotton containing $100 \mu \mathrm{L}$ of a $0.8 \%$ MJ solution onto the inside wall of a $20 \mathrm{~L}$-container and wrapped in a transparent plastic bag. For mock treatments a piece of cotton containing $100 \mu \mathrm{L}$ ethanol was used [66].

\subsection{Oxidative Stress Treatments}

Four-week-old soil-grown plants were sprayed with freshly-prepared solutions of $\mathrm{H}_{2} \mathrm{O}_{2}(500 \mathrm{mM})$ or methyl viologen $(30 \mu \mathrm{M})$, a herbicide that produces superoxide radicals which are converted into $\mathrm{H}_{2} \mathrm{O}_{2}$ by superoxide dismutase in chloroplasts. Both chemicals were dissolved in water. Control plants were sprayed with water.

\subsection{Growth Conditions of Cat2-2 Plants}

Arabidopsis wild type and cat2-2 [6] seeds were sown on MS plates as described above. After two days at $0{ }^{\circ} \mathrm{C}$, the plates were transferred to a growth cabinet with high $\mathrm{CO}_{2}$ level $(3000 \mathrm{ppm})$, at a light intensity of $80 \mu \mathrm{mol}$ photons. $\mathrm{m}^{-2} \cdot \mathrm{s}^{-1}$, long day conditions $(16 \mathrm{~h} \mathrm{light} / 8 \mathrm{~h}$ dark $)$ and $22^{\circ} \mathrm{C}$ day $/ 18^{\circ} \mathrm{C}$ night temperatures. After two weeks of growth under the above-mentioned non-photorespiratory conditions, we induced the metabolic formation of $\mathrm{H}_{2} \mathrm{O}_{2}$ by transferring the plates 2 hours after the light switch on to a growth chamber with normal air $\left(\mathrm{CO}_{2} \sim 380 \mathrm{ppm}\right)$, while keeping all other parameters unchanged. After 8 hours under photorespiratory conditions plants were collected in liquid $\mathrm{N}_{2}$ and stored at $-80^{\circ} \mathrm{C}$ for subsequent analysis.

\section{7. $\mathrm{H}_{2} \mathrm{O}_{2}$ Quantification}

The optimized Amplex Red-based quantitation method by [67] was applied for $\mathrm{H}_{2} \mathrm{O}_{2}$ estimation. Harvested seedlings ( $50 \mathrm{mg} F W$ ) were ground in liquid $\mathrm{N}_{2}$ and re-suspended in $250 \mu \mathrm{L} 50 \mathrm{mM}$ sodium phosphate buffer. The re-suspended tissue was vortexed for $10 \mathrm{~s}$ and shaken continuously at room temperature for $30 \mathrm{~min}$. The samples were centrifuged for $5 \mathrm{~min}$ at 12,000 rpm at room temperature, and the supernatant was transferred to new tubes. The collected supernatant was re-centrifuged for additional $2 \mathrm{~min}$. The supernatant was transferred to new tubes and kept on ice until analysis (on 
same day). $\mathrm{H}_{2} \mathrm{O}_{2}$ quantification was conducted according to the manufacturer protocol of Amplex ${ }^{\circledR}$ Red Hydrogen Peroxide/Peroxidase Assay Kit.

\subsection{RNA Isolation and cDNA Synthesis}

After the indicated times for each treatment, the whole rosettes were collected in liquid nitrogen and stored at $-80^{\circ} \mathrm{C}$. After grinding in liquid nitrogen, $70 \mathrm{mg}$ plant tissue was used for RNA extraction using the Promega Kit (SV Total RNA Isolation System, spin protocol). The integrity of RNA was tested by gel electrophoresis and quantified by NanoDrop spectrophotometer (ND-1000). For cDNA synthesis, the same amount of RNA (from 1000 to $2000 \mathrm{ng}$ ) was used and reverse transcriptase system (SuperScript III, Invitrogen) was used.

For primer design, the Primer Express 2.0 software (Applied Biosystems) was used. The primers were selected to amplify segments of cDNA of about 100-150 bp and close to the $3^{\prime}$ prime end of the gene. The primer pair used for HSP17.4CI (At3g46230) was as follows; forward primer: TCATGAGGAGGTTTCGGTTGC; reverse primer: CTCTCCTGAACTTTCGGCACC. As an internal control, the following ACTIN primer mixture was used: Forward universal ACTIN AGTGGTCGTACAACCGGTATTGT, ACTIN2 (At3g18780) reverse GATGGCATGAGGAAGAGAGAAAC, ACTIN7 (At5g09810) reverse GAGGAAGAGCATTCCCCTCGTA, and ACTIN8 (At1g49240) reverse GAGGATAGCATGTGGAACTGAGAA.

\subsection{Real-time RT-PCR}

For quantitative RT-PCR analysis, $6 \mu \mathrm{L}$-reactions consisted of $3 \mu \mathrm{L}$ SYBR Green master mix reagent (Applied Biosystems), $2 \mu \mathrm{L}$ primer mixture (forward and reverse, $1 \mu \mathrm{M}$ each) and $1 \mu \mathrm{l}$ cDNA (containing the equivalent of $10 \mathrm{ng}$ RNA) were used. Quantitative RT-PCR was performed with an ABI PRISM 7900 Sequence Detection System (SDS) (Applied Biosystems) using SYBR Green to monitor the real-time synthesis of double-stranded DNA. The following thermal cycles were applied; Stage $1: 95^{\circ} \mathrm{C} 10 \mathrm{~min}$, stage 2: 45 cycles of $95^{\circ} \mathrm{C} 15 \mathrm{~s}$ and $60^{\circ} \mathrm{C} 1 \mathrm{~min}$, stage 3: one cycle of $95^{\circ} \mathrm{C} 2 \mathrm{~min}, 60^{\circ} \mathrm{C} 15 \mathrm{~s}, 95^{\circ} \mathrm{C} 15 \mathrm{~s}$.

SDS 2.2.2 software (Applied Biosystems) was used to produce amplification plots and dissociation curves of the PCR results. For all amplification plots the Rn (normalized reporter signal) was set to 0.2 to get the threshold cycle $\left(C_{t}\right)$ values. Linear regression analysis (LinReg PCR software) has been applied to calculate the primer efficiency (E value) of each primer pair. The average of primer efficiency for each primer pair in all samples was calculated after excluding the primer efficiencies with $\mathrm{R}$ square less than 0.998. The relative expression of each gene (compared to ACTIN) was calculated using the following equation: $\mathrm{E}_{\mathrm{S}}{ }^{\wedge(-\mathrm{CtS})} / \mathrm{E}_{\mathrm{A}}{ }^{\wedge(-\mathrm{CtA})}$, where $\mathrm{E}_{\mathrm{S}}$ is the average primer efficiency of the primer pair for this gene, $\mathrm{E}_{\mathrm{A}}$ is that for $A C T I N, \mathrm{C}_{\mathrm{tS}}$ is the threshold cycle for the studied gene and $\mathrm{C}_{\mathrm{tA}}$ is that for ACTIN [68]. Standard deviation has been calculated from three replicates of each treatment.

\subsection{Statistical Analysis}

Before performing analysis of variance (ANOVA), the data was tested for its normality of distribution and homogeneity of variance, and whether log-transformation was necessary. The significance of variation in the expression data under various treatments was assessed using one-way ANOVA. The significant differences between the means were identified using Tukey's HSD test at $p<$ 0.05. For HSP17.4CI expression in cat2-2 plants and $\mathrm{H}_{2} \mathrm{O}_{2}$ quantification experiments, the Student's $\mathrm{t}$-test was used to evaluate the difference between genotypes (wild type (WT) and cat2-2). All statistical analyses were performed using SPSS 15.0 software 9 (SPSS Inc., 2006, Chicago, IL, USA).

Supplementary Materials: Supplementary materials can be found at http:/www.mdpi.com/1422-0067/20/13/ 3201/s1.

Author Contributions: Conceptualization, N.S., K.K., V.G.M. and P.M.S.; Formal analysis, N.S. and M.H.; Funding acquisition, V.G.M. and P.M.S.; Investigation, N.S. and K.K.; Methodology, N.S. and M.H.; Resources, K.K., V.G.M. and P.M.S.; Writing - original draft, N.S.; Writing - review \& editing, K.K., M.H., V.G.M. and P.M.S. 
Funding: This work was funded by the Australian Research Council (DP140103363), grants of the Deutsche Forschungsgemeinschaft (DFG, German Research Foundation) under Germany's Excellence Strategy - EXC 2048/1

- Project ID: 390686111 and EXC 1028 to VGM, and the Egyptian Ministry of Higher Education.

Acknowledgments: We thank Ebrehem Eid for his help performing the statistical analysis.

Conflicts of Interest: The authors declare no conflict of interest.

\section{References}

1. Petrov, V.D.; Van Breusegem, F. Hydrogen peroxide - a central hub for information flow in plant cells. $A o B$ Plants 2012, 2012, pls014. [CrossRef] [PubMed]

2. Xia, X.J.; Zhou, Y.H.; Shi, K.; Zhou, J.; Foyer, C.H.; Yu, J.Q. Interplay between reactive oxygen species and hormones in the control of plant development and stress tolerance. J. Exp. Bot. 2015, 66, 2839-2856. [CrossRef] [PubMed]

3. Caverzan, A.; Piasecki, C.; Chavarria, G.; Stewart, C.N., Jr.; Vargas, L. Defenses against ROS in crops and weeds: The effects of interference and herbicides. Int. J. Mol. Sci. 2019, 20, 1086. [CrossRef] [PubMed]

4. Mittler, R.; Vanderauwera, S.; Suzuki, N.; Miller, G.; Tognetti, V.B.; Vandepoele, K.; Gollery, M.; Shulaev, V.; Van Breusegem, F. ROS signaling: The new wave. Trends Plant Sci. 2011, 16, 300-309. [CrossRef] [PubMed]

5. Balazadeh, S.; Jaspert, N.; Arif, M.; Mueller-Roeber, B.; Maurino, V.G. Expression of ROS-responsive genes and transcription factors after metabolic formation of $\mathrm{H}_{2} \mathrm{O}_{2}$ in chloroplasts. Front. Plant Sci. 2012, 3, 234. [CrossRef] [PubMed]

6. Sewelam, N.; Jaspert, N.; Van Der Kelen, K.; Tognetti, V.B.; Schmitz, J.; Frerigmann, H.; Maurino, V.G. Spatial $\mathrm{H}_{2} \mathrm{O}_{2}$ signaling specificity: $\mathrm{H}_{2} \mathrm{O}_{2}$ from chloroplasts and peroxisomes modulates the plant transcriptome differentially. Mol. Plant 2014, 7, 1191-1210. [CrossRef] [PubMed]

7. Sewelam, N.; Kazan, K.; Schenk, P.M. Global plant stress signaling: Reactive oxygen species at the cross-road. Front. Plant Sci. 2016, 7, 187. [CrossRef] [PubMed]

8. Katano, K.; Honda, K.; Suzuki, N. Integration between ROS regulatory systems and other signals in the regulation of various types of heat responses in plants. Int. J. Mol. Sci. 2018, 19, 3370. [CrossRef]

9. Kollist, H.; Zandalinas, S.; Sengupta, S.; Nuhkat, M.; Kangasjärvi, J.; Mittler, R. Rapid responses to abiotic stress: Priming the landscape for the signal transduction network. Trends Plant Sci. 2019, 24, 25-37. [CrossRef]

10. Miller, G.; Mittler, R. Could heat shock transcription factors function as hydrogen peroxide sensors in plants? Annals Bot. 2006, 98, 279-288. [CrossRef]

11. Scarpeci, T.E.; Zanor, M.I.; Valle, E.M. Investigating the role of plant heat shock proteins during oxidative stress. Plant Signal. Behav. 2008, 3, 856-857. [CrossRef] [PubMed]

12. Mubarakshina, M.M.; Ivanov, B.N.; Naydov, I.A.; Hillier, W.; Badger, M.R.; Krieger-Liszkay, A. Production and diffusion of chloroplastic $\mathrm{H}_{2} \mathrm{O}_{2}$ and its implication to signaling. J. Exp. Bot. 2010, 61, 3577-3587. [CrossRef] [PubMed]

13. Borisova, M.M.; Kozuleva, M.A.; Rudenko, N.N.; Naydov, I.A.; Klenina, I.B.; Ivanov, B.N. Photosynthetic electron flow to oxygen and diffusion of hydrogen peroxide through the chloroplast envelope via aquaporins. Biochim. Biophys. Acta 2012, 1817, 1314-1321. [CrossRef] [PubMed]

14. Gasch, A.; Spellman, P.; Kao, C.; Harel, O.; Eisen, M.; Storz, G.; Botstein, D.; Brown, P.O. Genomic expression programs in the response of yeast cells to environmental changes. Mol. Biol. Cell 2000, 11, 4241-4257. [CrossRef]

15. Desikan, R.; Soheila, A.H.; Hancock, J.T.; Neill, S.J. Regulation of the Arabidopsis transcriptome by oxidative stress. Plant physiol. 2001, 127, 159-172. [CrossRef]

16. Scarpeci, T.E.; Zanor, M.I.; Carrillo, N.; Mueller-Roeber, B.; Valle, E.M. Generation of superoxide anion in chloroplasts of Arabidopsis thaliana during active photosynthesis: A focus on rapidly induced genes. Plant Mol. Biol. 2008, 66, 361-378. [CrossRef]

17. Vierling, E. The roles of heat shock proteins in plants. Ann. Rev. Plant Physiol. Plant Mol. Biol. 1991, 432, 579-620. [CrossRef]

18. Boston, R.S.; Viitanen, P.V.; Vierling, E. Molecular chaperones and protein folding in plants. In Post-Transcriptional Control of Gene Expression in Plants; Filipowicz, W., Hohn, T., Eds.; Springer: Dordrecht, Netherlands, 1996; Volume 32, (1-2), pp. 191-222. 
19. Grigorova, B.; Vaseva, I.I.; Demirevska, K.; Feller, U. Expression of selected heat shock proteins after individually applied and combined drought and heat stress. Acta Physiol. Plant. 2011, 33, 2041. [CrossRef]

20. Cao, F.; Cheng, H.; Cheng, S.; Li, L.; Xu, F.; Yu, W.; Yuan, H. Expression of selected Ginkgo biloba heat shock protein genes after cold treatment could be induced by other abiotic stress. Int. J. Mol. Sci. 2012, 13, 5768. [CrossRef]

21. Li, Z.Y.; Long, R.C.; Zhang, T.J.; Yang, Q.C.; Kang, J.M. Molecular cloning and characterization of the MsHSP17.7 gene from Medicago sativa L. Mol. Biol. Rep. 2016, 43, 815-826. [CrossRef]

22. Muthusamy, S.K.; Dalal, M.; Chinnusamy, V.; Bansal, K.C. Genome-wide identification and analysis of biotic and abiotic stress regulation of small heat shock protein (HSP20) family genes in bread wheat. J. Plant Physiol. 2017, 211, 100-113. [CrossRef] [PubMed]

23. Liu, J.; Wang, R.; Liu, W.; Zhang, H.; Guo, Y.; Wen, R. Genome-wide characterization of heat-shock protein 70s from Chenopodium quinoa and expression analyses of Cqhsp70s in response to drought stress. Genes (Basel) 2018, 9, 35. [CrossRef] [PubMed]

24. Wang, W.; Vinocur, B.; Shoseyov, O.; Altman, A. Role of plant heat shock proteins and molecular chaperones in the abiotic stress response. Trends Plant Sci. 2004, 9, 244-252. [CrossRef] [PubMed]

25. Fu, X. Chaperone function and mechanism of small heat-shock proteins. Acta Biochim. Biophys. Sin. (Shanghai) 2014, 46, 347-356. [CrossRef] [PubMed]

26. Lavania, D.; Siddiqui, M.H.; Al-Whaibi, M.H.; Singh, A.K.; Kumar, R.; Grover, A. Genetic approaches for breeding heat stress tolerance in faba bean (Vicia faba L.). Acta Physiol. Plant. 2015, 37, 1737. [CrossRef]

27. Fragkostefanakis, S.; Röth, S.; Schleiff, E.; Scharf, K.D. Prospects of engineering thermotolerance in crops through modulation of heat stress transcription factor and heat shock protein networks. Plant Cell Environ. 2015, 38, 1881-1895. [CrossRef]

28. Jiang, Y.; Zheng, Q.; Chen, L.; Liang, Y.; Wu, J. Ectopic overexpression of maize heat shock transcription factor gene $\mathrm{ZmHsf04}$ confers increased thermo and salt-stress tolerance in transgenic Arabidopsis. Acta Physiol. Plant. 2018, 40, 9. [CrossRef]

29. Sable, A.; Rai, K.M.; Choudhary, A.; Yadav, V.K.; Agarwal, S.K.; Sawant, S.V. Inhibition of heat shock proteins HSP90 and HSP70 induce oxidative stress, suppressing cotton fiber development. Sci. Rep. 2018, 8, 3620. [CrossRef]

30. Vierling, E. The small heat shock proteins in plants are members of an ancient family of heat induced proteins. Acta Physiol. Plant. 1997, 19, 539. [CrossRef]

31. Nakamoto, H.; Vigh, L. The small heat shock proteins and their clients. Cell Mol. Life Sci. 2007, 64, $294-306$. [CrossRef]

32. Waters, E.R. The evolution, function, structure, and expression of the plant sHSPs. J. Exp. Bot. 2013, 64, 391-403. [CrossRef] [PubMed]

33. He, Y.; Fan, M.; Sun, Y.; Li, L. Genome-wide analysis of watermelon HSP20s and their expression profiles and subcellular locations under stresses. Int. J. Mol. Sci. 2018, 20, 12. [CrossRef] [PubMed]

34. Sewelam, N.; Oshima, Y.; Mitsuda, N.; Ohme-Takagi, M. A step towards understanding plant responses to multiple environmental stresses: A genome-wide study. Plant Cell Environ. 2014, 37, 2024-2035. [CrossRef] [PubMed]

35. Sun, W.; Van Montagu, M.; Verbruggen, N. Small heat shock proteins and stress tolerance in plants. Biochim. Biophys. Acta 2002, 1577, 1-9. [CrossRef]

36. Yang, M.; Zhang, Y.; Zhang, H.; Wang, H.; Wei, T.; Che, S.; Zhang, L.; Hu, B.; Long, H.; Song, W.; et al. Identification of MsHsp20 gene family in Malus sieversii and functional characterization of MsHsp16.9 in heat tolerance. Front. Plant Sci. 2017, 8, 1761. [CrossRef] [PubMed]

37. Dobson, C.M. Protein folding and misfolding. Nature 2003, 426, 884-890. [CrossRef]

38. McHaourab, H.S.; Godar, J.A.; Stewart, P.L. Structure and mechanism of protein stability sensors: Chaperone activity of small heat shock proteins. Biochem. 2009, 48, 3828-3837. [CrossRef]

39. Jacob, P.; Hirt, H.; Bendahmane, A. The heat-shock protein/chaperone network and multiple stress resistance. Plant Biotechnol. J. 2017, 15, 405-414. [CrossRef]

40. Hilton, G.R.; Lioe, H.; Stengel, F.; Baldwin, A.J.; Benesch, J.L.P. Small heat-shock proteins: Paramedics of the cell. Topics Curr. Chem. 2013, 328, 69-98. 
41. Mogk, A.; Schlieker, C.; Friedrich, K.L.; Schönfeld, H.J.; Vierling, E.; Bukau, B. Refolding of substrates bound to small HSPs relies on a disaggregation reaction mediated most efficiently by ClpB/DnaK. J. Biol. Chem. 2003, 278, 31033-31042. [CrossRef]

42. Balogi, Z.; Torok, Z.; Balogh, G.; Josvay, K.; Shigapova, N.; Vierling, E.; Vígh, L.; Horváth, I. “Heat shock lipid" in cyanobacteria during heat/light-acclimation. Arch. Biochem. Biophys. 2005, 436, 346-354. [CrossRef] [PubMed]

43. Neta-Sharir, I.; Isaacson, T.; Lurie, S.; Weiss, D. Dual role for tomato heat shock protein 21: Protecting photosystem II from oxidative stress and promoting color changes during fruit maturation. Plant Cell 2005, 17, 1829-1838. [CrossRef]

44. Guo, S.J.; Zhoua, H.Y.; Zhanga, X.S.; Lic, X.G.; Menga, Q.W. Overexpression of CaHSP26 in transgenic tobacco alleviates photoinhibition of PSII and PSI during chilling stress under low irradiance. J. Plant Physiol. 2007, 164, 126-136. [CrossRef] [PubMed]

45. Mu, C.; Zhang, S.; Yu, G.; Chen, N.; Li, X.; Liu, H. Overexpression of small heat shock protein LimHSP16.45 in Arabidopsis enhances tolerance to abiotic stresses. PLoS ONE 2013, 8, e82264. [CrossRef] [PubMed]

46. Sewelam, N.; Kazan, K.; Thomas-Hall, S.; Kidd, B.N.; Manners, J.M.; Schenck, P.M. Ethylene response factor 6 is a regulator of reactive oxygen species signaling in Arabidopsis. PLoS ONE 2013, 8, e70289. [CrossRef] [PubMed]

47. Park, C.J.; Seo, Y.S. Heat shock proteins: A review of the molecular chaperones for plant immunity. Plant Pathol. J. 2015, 31, 323-333. [CrossRef] [PubMed]

48. Qu, A.L.; Ding, Y.F.; Jiang, Q.; Zhu, C. Molecular mechanisms of the plant heat stress response. Biochem. Biophys. Res. Commun. 2013, 432, 203-207. [CrossRef] [PubMed]

49. Glazebrook, J. Contrasting mechanisms of defense against biotrophic and necrotrophic pathogens. Anпu. Rev. Phytopathol. 2005, 43, 205-227. [CrossRef]

50. Kotak, S.; Larkindale, J.; Lee, U.; von Koskull-Döring, P.; Vierling, E.; Scharf, K.D. Complexity of the heat stress response in plants. Curr. Opin. Plant Biol. 2007, 10, 310-316. [CrossRef]

51. Queval, G.; Issakidis-Bourguet, E.; Hoeberichts, F.A.; Vandorpe, M.; Gakière, B.; Vanacker, H.; Miginiac-Maslow, M.; Van Breusegem, F.; Noctor, G. Conditional oxidative stress responses in the Arabidopsis photorespiratory mutant cat2 demonstrate that redox state is a key modulator of daylength-dependent gene expression, and define photoperiod as a crucial factor in the regulation of $\mathrm{H}_{2} \mathrm{O}_{2}$-induced cell death. Plant $J$. 2007, 52, 640-657.

52. Davletova, S.; Schlauch, K.; Coutu, J.; Mittler, R. The zinc-finger protein Zat12 plays a central role in reactive oxygen and abiotic stress signaling in Arabidopsis. Plant Physiol. 2005, 139, 847-856. [CrossRef] [PubMed]

53. Uniport. Available online: https://www.uniprot.org/ (accessed on 28 May 2019).

54. The Arabidopsis Information Resource (TAIR). Available online: https://www.arabidopsis.org/index.jsp (accessed on 28 May 2019).

55. Wrzaczek, M.; Brosché, M.; Kangasjärvi, J. ROS signaling loops-production, perception, regulation. Curr. Opin. Plant Biol. 2013, 16, 575-582. [CrossRef] [PubMed]

56. Kaur, H.; Petla, B.P.; Kamble, N.U.; Singh, A.; Rao, V.; Salvi, P.; Ghosh, S.; Majee, M. Differentially expressed seed aging responsive heat shock protein OsHSP18.2 implicates in seed vigor, longevity and improves germination and seedling establishment under abiotic stress. Front. Plant Sci. 2015, 6, 713. [CrossRef] [PubMed]

57. Ham, D.J.; Moon, J.C.; Hwang, S.G.; Jang, C.S. Molecular characterization of two small heat shock protein genes in rice: Their expression patterns, localizations, networks, and heterogeneous overexpressions. Mol. Biol. Rep. 2013, 40, 6709-6720. [CrossRef] [PubMed]

58. Lee, J.H.; Yun, H.S.; Kwon, C. Molecular communications between plant heat shock responses and disease resistance. Mol. Cells 2012, 34, 109-116. [CrossRef] [PubMed]

59. Van Ooijen, G.; Lukasik, E.; Van Den Burg, H.A.; Vossen, J.H.; Cornelissen, B.J.; Takken, F.L. The small heat shock protein 20 RSI2 interacts with and is required for stability and function of tomato resistance protein I-2. Plant J. 2010, 63, 563-572. [CrossRef]

60. Larkindale, J.; Huang, B. Thermotolerance and antioxidant systems in Agrostis stolonifera: Involvement of salicylic acid, abscisic acid, calcium, hydrogen peroxide, and ethylene. J. Plant Physiol. 2004, 161, 405-413. [CrossRef] 
61. Watkins, J.M.; Chapman, J.M.; Muday, G.K. Abscisic acid-induced reactive oxygen species are modulated by flavonols to control stomata aperture. Plant physiol. 2017, 175, 1807-1825. [CrossRef]

62. Asad, M.A.U.; Zakari, S.A.; Zhao, Q.; Zhou, L.; Ye, Y.; Cheng, F. Abiotic stresses intervene with ABA signaling to induce destructive metabolic pathways leading to death: Premature leaf senescence in plants. Int. J. Mol. Sci. 2019, 20, 256. [CrossRef]

63. Del Río, L.A. ROS and RNS in plant physiology: An overview. J. Exp. Bot. 2015, 66, 2827-2837. [CrossRef]

64. Mittler, R. ROS are good. Trends Plant Sci. 2017, 22, 11-19. [CrossRef] [PubMed]

65. Murashige, T.; Skoog, F. A revised medium for rapid growth and bioassays with tobacco tissue cultures. Physiol. Plant. 1962, 15, 473-497. [CrossRef]

66. Schenk, P.M.; Kazan, K.; Wilson, I.; Anderson, J.P.; Richmond, T.; Somerville, S.C.; Manners, J.M. Coordinated plant defense responses in Arabidopsis revealed by microarray analysis. Proc. Natl. Acad. Sci. USA 2000, 97, 11655-11660. [CrossRef] [PubMed]

67. Chakraborty, S.; Hill, A.L.; Shirsekar, G.; Afzal, A.J.; Wang, G.L.; Mackey, D.; Bonello, P. Quantification of hydrogen peroxide in plant tissues using Amplex Red. Methods 2016, 15, 105-113. [CrossRef] [PubMed]

68. Czechowski, T.; Bari, R.P.; Stitt, M.; Scheible, W.R.; Udvardi, M.K. Real-time RT-PCR profiling of over 1400 Arabidopsis transcription factors: Unprecedented sensitivity reveals novel root- and shoot-specific genes. Plant J. 2004, 38, 366-379. [CrossRef] [PubMed]

(C) 2019 by the authors. Licensee MDPI, Basel, Switzerland. This article is an open access article distributed under the terms and conditions of the Creative Commons Attribution (CC BY) license (http://creativecommons.org/licenses/by/4.0/). 